\title{
Effect of early exposure to different feed presentations on feed sorting of dairy calves
}

\author{
E. K. Miller-Cushon, ${ }^{*}$ R. Bergeron, † K. E. Leslie,‡ G. J. Mason, $§$ and T. J. DeVries*1 \\ *Department of Animal and Poultry Science, University of Guelph, Kemptville Campus, 830 Prescott Street, Kemptville, ON, K0G 1J0, Canada \\ †Department of Animal and Poultry Science, University of Guelph, Campus d'Alfred, Alfred, ON, K0B 1A0, Canada \\ ‡Department of Population Medicine, Ontario Veterinary College, and \\ §Department of Animal and Poultry Science, University of Guelph, Guelph, ON, N1G 2W1, Canada
}

\begin{abstract}
This study examined how early exposure to different feed presentations affects development of feed sorting in dairy calves. Twenty Holstein bull calves were exposed for the first $8 \mathrm{wk}$ of life to 1 of 2 feed presentation treatments: concentrate and chopped grass hay $(<2.5 \mathrm{~cm})$ offered ad libitum at a ratio of $7: 3$ as a mixture (MIX), or as separate components $(\mathrm{COM})$. Calves received 8 $\mathrm{L} / \mathrm{d}$ of milk replacer $(1.2 \mathrm{~kg}$ of dry matter), with the amount progressively reduced after 5 wk to facilitate weaning by the end of wk 7 . All calves received the MIX diet in wk 9 to 11 and, subsequently, a novel total mixed ration (TMR; containing $40.5 \%$ corn silage, $22.0 \%$ haylage, $21.5 \%$ high-moisture corn, and $16.0 \%$ protein supplement) in wk 12 to 13 . Intake was recorded daily and calves were weighed twice a week. Fresh feed and orts were sampled on d 1 to 4 of wk $6,8,9,11,12$, and 13 for analysis of feed sorting, which was assessed through nutrient analysis for the MIX diet and particle size analysis for the TMR. The particle separator had 3 screens $(19,8$, and $1.18 \mathrm{~mm})$ producing long, medium, short, and fine particle fractions. Sorting of nutrients or particle fractions was calculated as the actual intake as a percentage of predicted intake; values $>100 \%$ indicate sorting for, whereas values $<100 \%$ indicate sorting against. Feed presentation did not affect dry matter intake or growth. Prior to weaning, all calves selected in favor of hay; MIX calves consumed more neutral detergent fiber (NDF) than predicted $(103.6 \%)$ and less nonfiber carbohydrates (NFC) than predicted (92.6\%), and $\mathrm{COM}$ calves consumed, as a percentage of dry matter intake, $40.3 \%$ hay (vs. $30 \%$ offered rate). In wk 8 , calves fed COM consumed more NFC than calves fed MIX (1.0 vs. $0.95 \mathrm{~kg} / \mathrm{d})$ and less NDF (0.43 vs. $0.54 \mathrm{~kg} / \mathrm{d}$ ), indicating greater selection in favor of concentrate. However, when provided the MIX diet, calves previously fed COM did not sort, whereas calves previously
\end{abstract}

Received February 6, 2013.

Accepted March 29, 2013.

${ }^{1}$ Corresponding author: tdevries@uoguelph.ca fed MIX consumed more NFC intake than predicted (103.2\%) and less NDF intake than predicted (97.6\%). Calves previously fed MIX maintained increased sorting after transition to the novel TMR, sorting against long particles (86.5\%) and for short (101.8\%) and fine $(101.2 \%)$ particles. These results indicate that initially providing dairy calves with solid feeds as separate components, compared with as a mixed ration, reduces the extent of feed sorting in the weeks after transition to a common ration.

Key words: dairy calf, feed sorting, feed presentation, learning

\section{INTRODUCTION}

It is common practice to provide dairy cattle a TMR with the goal of ensuring that a balanced ration is available over the course of the day (Coppock et al., 1981). However, both immature and mature dairy cattle actively sort TMR against long forage particles and in favor of the smaller grain particles, which are higher in starch and energy (Leonardi and Armentano, 2003; Greter et al., 2010a). Sorting of the ration affects nutrient content of the ration over the course of the day (DeVries et al., 2005), resulting in cows consuming an unbalanced ration. Due to the effects of feed sorting on nutrient composition and consistency of the ration, various recent studies have addressed factors that influence feed sorting. Problems associated with feed sorting are typically addressed by attempting to thwart sorting at the herd level, through nutrition and feeding management (Leonardi et al., 2005; Miller-Cushon and DeVries, 2009; DeVries et al., 2005). However, dairy cattle vary both in the degree and pattern of feed sorting (Leonardi and Armentano, 2003), suggesting that feed and flavor preferences, sorting ability, and sorting inclination may vary between animals.

It is possible that early experiences may influence the development of feed sorting, contributing to the individual variability in feed sorting observed in adult cattle. There is substantial evidence that early feed experiences have the potential to shape feed prefer- 
ences and feeding behavior of ruminants later in life. For example, when tested later in life, ruminants have been found to exhibit preferences for flavors (Simitzis et al., 2008) and feed types (Arnold and Maller, 1977; Provenza and Balph, 1988) to which they were exposed in the first months of life. There is also evidence that motor skills develop in response to early feed exposure, with animals feeding more efficiently when they have had previous experience with that type of plant (Arnold and Maller, 1977; Flores et al., 1989).

Despite commonly being fed a TMR later in life, dairy calves are often provided a limited number of feed types separately early in life. It is common practice to provide milk-fed calves with concentrate and, occasionally, forage (Coverdale et al., 2004). Provision of a mixed ration to calves before weaning has not yet been widely explored. It has been suggested that use of a TMR for young heifers may result in better balance of nutrient intake by avoiding individual preferences for forage or concentrate (Borland and Kesler, 1979). When provided concentrate and forage as separate components or as a top-dressed ration, weaned heifers consumed the concentrate component before consuming the forage (DeVries and von Keyserlingk, 2009; Greter et al., 2010a). In contrast, provision of a TMR has been found to increase NDF intake due to reduced selection in favor of concentrate (Greter et al., 2010a). Greter et al. (2010b) followed 11-mo-old heifers previously exposed to either concentrate and hay as a top-dressed ration or as a TMR and found no long-term differences in feed sorting once all heifers were fed a novel TMR. It is possible, however, that differences in dietary selection resulting from previous feed presentation exposure may persist for a longer period of time if the experience with feed presentation occurs at a younger age. Weaning is considered a formative period in the development of feeding behavior, as animals are rapidly increasing intake of solid feed, developing feeding motor skills, and forming feed preferences that can be quite persistent (Arnold and Maller, 1977; Squibb et al., 1990). Thus, exposure to different feed presentations at this stage may have a longer-term influence on feeding behavior.

Therefore, the objective of this study was to determine how feed presentation may affect development of feed sorting in dairy calves. Specifically, this study determined the effect of feed presentation on the dietary selection of dairy calves during the milk-feeding stage. Postweaning, the effects of prior exposure to different feed presentations on feed sorting was assessed once all calves were provided, first, a mixed ration composed of familiar feed components and, second, a novel TMR. We hypothesized that calves provided hay and concentrate as separate components early in life would select greater quantities of concentrate than calves provided hay and concentrate as a mixture and, consequently, consume a diet higher in carbohydrates and lower in fiber. Thus, we hypothesized that, upon transition to the mixed ration, calves previously exposed to these feed types as separate components would sort to a greater extent than calves previously familiar with the mixed ration to maintain this pattern of selection in favor of the concentrate component. Further, we hypothesized that differences in feed sorting would persist after transition to a novel TMR.

\section{MATERIALS AND METHODS}

\section{Animals and Housing}

Twenty male Holstein calves were used in this study. Calves received colostrum and were enrolled in the study within $24 \mathrm{~h}$ of birth. All calves received intramuscular injections of $2 \mathrm{~mL}$ of a vitamin supplement containing vitamins A, D, and E (E-Master, Vétoquinol Canada Inc., Lavaltrie, Canada) and $1 \mathrm{~mL}$ of selenium (Dystosel, Pfizer Animal Health, Kirkland, Canada) and a subcutaneous injection of $1 \mathrm{~mL}$ of tulathromycin (Draxxin, Pfizer Animal Health) as a preventive measure to reduce incidence of illness (Stanton et al., 2013).

Calves were housed in individual pens $(1.2 \times 1.8 \mathrm{~m}$; width $\times$ depth) at the University of Guelph, Kemptville Campus Dairy Education and Research Centre (Kemptville, Canada) and were managed according to the standard operating procedures of this research station, in accordance with guidelines set by the Canadian Council on Animal Care (CCAC, 2009). The front of each pen had 2 openings for access to pails (diameter $=25.4 \mathrm{~cm}$, height $=23.0 \mathrm{~cm}$, capacity $=8$ L) mounted on the outside. A third pail of the same size was mounted at the rear of the pen and filled with fresh water daily. The interior of each pen was bedded with wood shavings; bedding was replaced weekly and fresh bedding was added as needed. Pens were located under a 3 -sided, roofed shelter to protect from excessive exposure to the elements.

\section{Milk Feeding Procedure}

During the milk-feeding stage (wk 1-7), all calves were fed acidified milk replacer via an artificial teat (Peach Teats, Skellerup Industries Ltd., Woolston, New Zealand). The feeding setup involved the teat mounted at the front of the pen, attached to a tube fitted with a one-way valve running into buckets placed outside the pen. All buckets, lines, and teats were cleaned daily. Calves were fed $22 \% \mathrm{CP}$ and $18 \%$ fat milk replacer (Shur-Gain High Performance Milk Replacer, Nutreco Canada Inc., Guelph, Canada) mixed as indicated at 
a rate of $150 \mathrm{~g} / \mathrm{L}$. Milk replacer was mixed daily in a sufficient volume to feed all calves. At the time of preparation, a prediluted form of $9.8 \%$ formic acid (The Acidified Milk Solution, NOD Apiary Products Ltd., Frankford, Canada) was added to acidify the milk replacer to a target $\mathrm{pH}$ between 4.0 and 4.5 to prevent microbial growth over the course of the day.

All calves were fed a fixed amount of $8 \mathrm{~L} / \mathrm{d}(1.2 \mathrm{~kg}$ of DM) twice daily, at 0800 and $1600 \mathrm{~h}$, for the first 4 wk. To facilitate weaning, the amount of milk replacer offered was decreased to $6 \mathrm{~L} / \mathrm{d}(0.9 \mathrm{~kg}$ of $\mathrm{DM})$ during wk $5,4 \mathrm{~L} / \mathrm{d}(0.6 \mathrm{~kg}$ of $\mathrm{DM})$ during wk 6 , and then decreased progressively during wk 7 (in $\mathrm{d} 1-4$ calves were offered $3 \mathrm{~L} / \mathrm{d}$ and in d 5-7 calves were offered $2 \mathrm{~L} / \mathrm{d}$ ). Given the study objective of assessing effects of solid feed presentation, calves were provided milk at a controlled rate to reduce variability in milk intake across calves, as well as to encourage exposure to solid feed, compared with the variable milk intakes and low solid feed intake observed in calves provided milk ad libitum (Appleby, 2001; Jasper and Weary, 2002). However, in comparison to the conventionally provided rate of $10 \%$ of BW, or 4 to $5 \mathrm{~L} / \mathrm{d}$ (Appleby, 2001), milk was provided at an elevated fixed rate in the present study (as previously demonstrated effective; Khan et al., 2011; Montoro et al., 2013) to alleviate welfare concerns of hunger associated with highly restricted milk feeding (De Paula Vieira et al., 2008).

\section{Experimental Design and Diets}

Upon enrollment, calves were randomly assigned to 1 of 2 feed presentation treatments: (1) concentrate and chopped ryegrass hay $(<2.5 \mathrm{~cm})$ offered at a ratio of $7: 3$ as a mixture (MIX); and (2) concentrate and chopped hay $(<2.5 \mathrm{~cm})$ offered at a ratio of $7: 3$ as separate components (COM), as detailed below. The hay was chopped using a New Holland 355 grinder-mixer (New Holland Inc., New Holland, PA) to pass through a 2.54$\mathrm{cm}$ mesh. Fresh feed was offered once daily, at $1000 \mathrm{~h}$, in quantities such that $>15 \%$ orts were obtained. Appropriate quantities of concentrate $(0.7 \times$ total offered amount) and hay $(0.3 \times$ total offered amount $)$ were weighed out daily for all calves. For COM calves, the feed types were placed into separate buckets. For MIX calves, the feed types were mixed together thoroughly by hand and then placed in a single bucket. To account for any side preference, the position of the hay and concentrate feed buckets for COM calves was switched daily. Calves remained on their respective feed presentation treatments throughout the milk-feeding stage (wk 1-7) and for 1 wk following removal of milk (wk 8).

Following this period of feed presentation exposure, all calves were offered the MIX diet for 3 wk (wk 9-11). At the beginning of wk 12, calves were offered a novel TMR for $2 \mathrm{wk}$ (wk 12 and 13). The ingredient and chemical composition of all diets is given in Table 1 .

Throughout the study, orts were removed daily immediately before delivery of fresh feed. Individual feed intake was determined daily by weighing the amount of feed offered and the amount refused. Actual feeding level (\% orts) was compared between treatments to ensure that treatment was not confounded with feeding level, which has been found to affect degree of feed sorting (Leonardi and Armentano, 2007; Miller-Cushon and DeVries, 2010).

Initial BW did not differ between treatments (43.7 vs. $44.1 \mathrm{~kg}$; MIX vs. $\mathrm{COM} ; \mathrm{SE}=1.3 ; P=0.6$ ). Calves were weighed using a calibrated digital floor scale (P2000 floor scale, Avery Weigh-Tronix, Pointe-Claire,

Table 1. Chemical composition of feed components and mixed rations (mean $\pm \mathrm{SD} ; \mathrm{DM}$ basis)

\begin{tabular}{lcccc}
\hline Chemical composition $^{1}$ & Hay $^{2}$ & Concentrate $^{3}$ & Mixed ration $^{4}$ & Novel TMR $^{5}$ \\
\hline DM, \% & $91.7 \pm 1.5$ & $90.4 \pm 0.9$ & $91.3 \pm 0.5$ & $55.3 \pm 3.5$ \\
NDF, \% of DM & $59.2 \pm 1.6$ & $15.1 \pm 1.7$ & $26.1 \pm 3.2$ & 29.5 \\
ADF, \% of DM & $36.5 \pm 1.2$ & $7.9 \pm 1.2$ & $15.0 \pm 2.7$ & 19.4 \\
NFC, \% of DM & $16.0 \pm 1.7$ & $53.7 \pm 5.7$ & $43.2 \pm 4.2$ & 46.8 \\
CP, \% of DM & $13.7 \pm 1.3$ & $21.1 \pm 2.2$ & $19.4 \pm 1.6$ & 16.2 \\
ME, Mcal/kg of DM & $2.1 \pm 0.07$ & $2.9 \pm 0.04$ & $2.7 \pm 0.07$ & 2.7 \\
\hline
\end{tabular}

${ }^{1}$ Values were obtained from chemical analysis of feed samples. NFC $=100-(\% \mathrm{CP}+\% \mathrm{NDF}+\%$ fat $+\%$ ash). $\mathrm{ME}=$ total digestible nutrients $(\mathrm{TDN}) \times 0.04409 \times 0.82$ (calculated according to NRC, 2001, equations).

${ }^{2}$ Second-cut ryegrass hay.

${ }^{3}$ Dairy calf starter concentrate supplied by Rooney's Feeds (Iroquois, ON) containing (on as-is basis) 36.5\% corn, $28 \%$ calf starter supplement (Shur-Gain, Nutreco Canada Inc., Guelph, ON, Canada), 20\% rolled barley, $2.5 \%$ dilute monensin sodium, $2 \%$ molasses, $1 \%$ soybean oil.

${ }^{4}$ Contained, as a percentage of DM, $70 \%$ concentrate and $30 \%$ hay (chopped $<2.5 \mathrm{~cm}$ ).

${ }^{5}$ Contained, as a percentage of DM, $40.5 \%$ corn silage (chemical composition was $7.5 \% \mathrm{CP}, 39.3 \%$ NDF, $48.6 \%$ NFC), $22.0 \%$ red clover haylage (chemical composition was $20.9 \% \mathrm{CP}, 42.9 \% \mathrm{NDF}, 29.9 \% \mathrm{NFC}$ ), $21.5 \%$ highmoisture corn (8.7\% CP, 8.2\% NDF, $78.3 \% \mathrm{NFC}), 16.0 \%$ protein supplement $(41.7 \% \mathrm{CP}, 14.9 \% \mathrm{NDF}, 23.1 \%$ NFC). 
Table 2. Particle size distribution of the novel TMR ration and its components offered in wk 12 to 13 (mean $\pm \mathrm{SD})$

\begin{tabular}{lccccr}
\hline $\begin{array}{l}\text { Particle size, \% of DM } \\
\text { retained on screen }\end{array}$ & Corn silage & $\begin{array}{c}\text { Red clover } \\
\text { haylage }\end{array}$ & $\begin{array}{c}\text { High-moisture } \\
\text { corn }\end{array}$ & $\begin{array}{c}\text { Protein } \\
\text { supplement }\end{array}$ & TMR $^{2}$ \\
\hline Long & $7.6 \pm 3.2$ & $17.9 \pm 8.9$ & $0.0 \pm 0.0$ & $0.0 \pm 0.0$ & $7.5 \pm 2.1$ \\
Medium & $54.0 \pm 10.4$ & $55.0 \pm 4.6$ & $60.2 \pm 0.4$ & $0.8 \pm 0.07$ & $42.4 \pm 3.4$ \\
Short & $36.7 \pm 6.7$ & $21.8 \pm 4.5$ & $34.1 \pm 0.8$ & $97.3 \pm 0.08$ & $40.5 \pm 4.4$ \\
Fine & $1.7 \pm 0.6$ & $5.3 \pm 3.0$ & $4.7 \pm 0.7$ & $1.9 \pm 0.1$ & $9.7 \pm 2.2$ \\
\hline
\end{tabular}

${ }^{1}$ Particle size determined by Penn State Particle Separator, which has a 19-mm screen (long), 8-mm screen (medium), 1.18-mm screen (short), and a pan (fine).

${ }^{2}$ Contained, as a percentage of DM, $40.5 \%$ corn silage, $22.0 \%$ red clover haylage, $21.5 \%$ high-moisture corn, $16.0 \%$ protein supplement.

Canada) at the same time of day on 2 consecutive days each week to obtain an accurate weekly weight.

\section{Feed Sampling and Analysis}

For determination of DM and nutrient content of the feed and assessment of daily DMI of the calves, fresh feed was sampled weekly and individual orts from each calf were sampled on d 1 and 4 of each week, just before removal and delivery of fresh feed. For calves fed COM, samples were taken of both concentrate and hay in wk 1 to 8 . Feed sorting was analyzed through additional samples taken of fresh feed and orts for calves fed MIX on d 1 to 4 of wk 6 and 8 and for all calves on d 1 to 4 of wk $9,11,12$, and 13 . All samples were immediately frozen at $-20^{\circ} \mathrm{C}$ until they were further analyzed.

Sorting of the MIX diet in wk 6, 8, 9, and 11 was assessed through nutrient analysis of the fresh and orts samples. Feed sorting of TMR is often analyzed by assessing particle size distributions of fresh feed and orts (Leonardi and Armentano, 2003) using the 3-screen Penn State Particle Separator (PSPS; Kononoff et al., 2003), which separates particles into 4 particle size fractions: long $(>19 \mathrm{~mm})$, medium $(<19$ and $>8 \mathrm{~mm})$, short $(<8$ and $>1.18 \mathrm{~mm})$, and fine $(<1.18 \mathrm{~mm})$.

However, as previously reported (Montoro et al., 2013), feed sorting is less accurately assessed through particle size analysis when the diet contains few ingredients with similar particle size distributions. In the present study, according to the PSPS, the short particle size fraction was greatest for both hay and concentrate; hay contained $11.7 \pm 9.9 \%$ long, $28.4 \pm 3.1 \%$ medium, $38.6 \pm 2.8 \%$ short, and $21.3 \pm 11.5 \%$ fine particles, whereas the concentrate contained $0.0 \pm 0.0 \%$ long, $15.0 \pm 6.1 \%$ medium, $78.7 \pm 2.6 \%$ short, and $6.3 \pm$ $3.6 \%$ fine particles. Given that the MIX diet contained only 2 feed components with distinct nutrient compositions (Table 1), nutrient analysis provided the clearest indication of dietary selection of this experimental diet. In contrast to the MIX diet, the novel TMR provided in wk 12 and 13 contained more ingredients and had a greater range of particle sizes (Table 2). Thus, samples of the novel TMR taken in wk 12 and 13 were analyzed for feed sorting using particle size analysis by the PSPS technique. After separation, the DM of each separated fraction was determined by oven-drying at $55^{\circ} \mathrm{C}$ for 48 h.

Samples taken for DM and chemical analysis, including samples taken for feed sorting in wk $6,8,9$, and 11 , were oven-dried at $55^{\circ} \mathrm{C}$ for $48 \mathrm{~h}$ and were ground to pass through a 1-mm screen (Wiley Mill, Arthur H. Thomas Co., Philadelphia, PA). Orts samples taken for sorting analysis were pooled by calf and week, and fresh samples were pooled by week. All samples were sent to Cumberland Valley Analytical Services Inc. (Maugansville, MD) for analysis of $\mathrm{DM}\left(135^{\circ} \mathrm{C}\right.$; AOAC International, 2000; method 930.15), ash $\left(535^{\circ} \mathrm{C}\right.$; AOAC International, 2000; method 942.05), ADF (AOAC International, 2000; method 973.18), NDF with heatstable $\alpha$-amylase and sodium sulfite (Van Soest et al., 1991), and $\mathrm{CP}(\mathrm{N} \times 6.25$; AOAC International, 2000; method 990.03; Leco FP-528 Nitrogen Analyzer, Leco, St. Joseph, MI). Nonfiber carbohydrate content was calculated as $100-(\% \mathrm{CP}+\% \mathrm{NDF}+\%$ fat $+\%$ ash) (NRC, 2001).

\section{Calculations and Statistical Analyses}

One calf (on COM treatment) was removed from the study during wk 6 for health reasons unrelated to the study; thus, data from only $9 \mathrm{COM}$ calves were analyzed in wk 7 to 11 .

For data from wk 6, 8, 9, and 11, feed sorting activity was assessed through actual intakes of NDF, ADF, CP, and NFC expressed as a percentage of the predicted intake of that nutrient (Leonardi and Armentano, 2003). The actual intake of each nutrient was calculated as the difference between the DM amount of each nutrient in the offered feed and that in the refused feed. The predicted intake for each nutrient was calculated as the product of total DMI multiplied by the DM percentage of that nutrient in the fed ration. Values equal to $100 \%$ 
indicate no sorting, $<100 \%$ indicate selective refusals (sorting against), and $>100 \%$ indicate preferential consumption (sorting for). For feed sorting data from wk 12 and 13, sorting activity of each particle size fraction (long, medium, short, fine) was calculated similarly, as the actual intake of each particle size fraction as a percentage of the predicted intake of that fraction (Leonardi and Armentano, 2003). To test whether calves were sorting the diet for each nutrient or particle size fraction (depending on the time period), sorting values for each calf were averaged within week over the $4 \mathrm{~d}$ in which sorting was assessed, generating 1 sorting value/calf per week. Sorting values for each nutrient or particle size fraction, as a percentage, were tested within treatment by week for a difference from 100 using $t$-tests within the MIXED procedure of SAS (SAS Institute, 2008).

All data were analyzed separately by time period: milk-feeding stage (wk 1-7), postweaning on separate feed exposure treatments (wk 8), while offered the common MIX diet (wk 9-11), and while offered the novel TMR (wk 12 and 13). Intake, BW, and ADG data were analyzed using the MIXED procedure of SAS (SAS Institute, 2008), treating week as a repeated measure. The model included the fixed effects of week, treatment, and week by treatment interaction and the random effect of calf within treatment. The autoregressive model was selected as the variance-covariance matrix structure on the basis of best fit according to Schwarz's Bayesian information criterion. Sorting data were also analyzed using the MIXED procedure of SAS (SAS Institute, 2008), treating week as a repeated measure when sorting data was assessed on multiple weeks within a time period. The model included the fixed effects of week, treatment, and week by treatment interaction and the random effect of calf within treatment. Compound symmetry was selected as the variance-covariance matrix structure for the sorting data on the basis of best fit according to Schwarz's Bayesian information criterion.

Assumptions of normality and homogeneity of variance were verified by plotting residuals from the model against predicted values. All values reported are least squares means. Significance was declared at $P \leq 0.05$ and trends reported if $0.05<P \leq 0.10$.

\section{RESULTS}

After the first week of age, all calves finished their milk allotment; thus, milk intake was held constant across treatments. Feed presentation did not affect DMI either preweaning ( 0.32 vs. $0.30 \mathrm{~kg} / \mathrm{d}$; MIX vs. COM, $\mathrm{SE}=0.036, P=0.77$ ) or in the week after weaning (in wk $8,2.08$ vs. $2.03 \mathrm{~kg} / \mathrm{d}, \mathrm{SE}=0.13, P=0.78)$. Total orts were similar between calves fed MIX and COM (in wk $8,15.8$ vs. $18.2 \%$ offered $\mathrm{DM}, \mathrm{SE}=3.1, P=0.4)$. For calves fed COM, concentrate orts were $12.2 \pm 5.2 \%$ offered concentrate DM (mean $\pm \mathrm{SD}$ ) and hay orts were $25.5 \pm 8.5 \%$ offered hay DM (mean $\pm \mathrm{SD}$ ). Calves fed MIX and COM had similar ADG throughout the milk-feeding stage $(0.76$ vs. $0.73 \mathrm{~kg} / \mathrm{d}, \mathrm{SE}=0.024, P$ $=0.39)$ and similar BW at weaning (73.9 vs. $74.1 \mathrm{~kg}$, $\mathrm{SE}=1.85, P=0.95$ ). Body weights were also similar between calves fed MIX and COM upon transition to the common diet (beginning of wk 9, 92.0 vs. $90.7 \mathrm{~kg}$, $\mathrm{SE}=2.8, P=0.74$ ).

Though feed presentation did not affect growth and intake, it did affect dietary selection. Prior to weaning (wk 6), MIX calves consumed more NDF and ADF and less NFC than predicted (Table 3), indicating selection against concentrate and in favor of hay (Table 1). Calves fed MIX increased selection in favor of concentrate over time. Immediately postweaning (wk 8), calves fed MIX tended to consume less NDF and more NFC than predicted, indicating selection against hay and for concentrate (Table 3). Similarly, the diet consumed by calves fed COM changed over time $(P<0.001)$. Calves fed COM consumed a diet lower in concentrate than the offered rate in wk $6(59.7 \pm 9.8$, as a $\%$ of DMI vs. $70 \%$ offered rate; $P=0.03$ ) and, as in calves fed MIX, consumed a diet higher in concentrate in wk $8(81.6 \pm$ 5.5 , as a $\%$ of DMI vs. $70 \%$ offered rate; $P<0.001$ ). Total intake of concentrate and hay by calves fed COM was $0.29 \pm 0.2$ and $0.12 \pm 0.05 \mathrm{~kg} / \mathrm{d}$, respectively, in wk 6 , and $1.74 \pm 0.6$ and $0.35 \pm 0.1 \mathrm{~kg} / \mathrm{d}$, respectively, in wk 8.

Nutrient intakes were similar $(P=0.91)$ between treatments in wk 6 , due to similar selection in favor of hay (Table 4). Although calves fed MIX and COM both selected in favor of concentrate and against hay in wk 8 , nutrient intakes differed between treatments. Calves fed COM consumed more NFC and less ADF and NDF than calves fed MIX $(P<0.04$; Table 4$)$, indicating that they were selecting a diet higher in concentrate than calves fed MIX.

Calves previously fed MIX and COM had similar ADG while fed MIX in wk 9 to 11 (1.11 vs. $1.05 \mathrm{~kg} / \mathrm{d}$; $\mathrm{SE}=0.04 ; P=0.29)$ and while fed the novel TMR in wk 12 and 13 (1.34 vs. $1.33 \mathrm{~kg} / \mathrm{d} ; \mathrm{SE}=0.07 ; P=0.92)$. Final BW at the end of wk 13 did not differ between calves exposed to MIX early in life and calves exposed to $\mathrm{COM}$ (134.1 vs. $131.4 ; \mathrm{SE}=3.1 ; P=0.53$ ). Orts were similar between calves previously fed MIX and COM in wk 9 to 13 (14.4\% vs. $15.7 \%$ offered DM; SE $=2.8 ; P=0.50$ ).

Previous exposure to different feed presentations had a carry-over effect on feed sorting, as assessed by nutrient intake as a percentage of predicted intake. After transition to the common MIX ration, calves previously 
Table 3. Dietary selection, as assessed through nutrient intake, by calves provided a mixed ration (MIX) ${ }^{1}$ during the milk-feeding stage (measured during wk 6) and in the week following weaning (wk 8; mean \pm SD) ${ }^{2}$

\begin{tabular}{lcc}
\hline $\begin{array}{l}\text { Nutrient intake, } \\
\% \text { of predicted intake }\end{array}$ & & \\
& Wk 6 & Wk 8 \\
\hline NDF & $103.6 \pm 2.8^{*}$ & $99.3 \pm 0.8 \dagger$ \\
ADF & $102.7 \pm 0.9^{*}$ & $99.9 \pm 1.0$ \\
NFC & $92.6 \pm 1.9^{* *}$ & $100.8 \pm 0.4 \dagger$ \\
CP & $98.4 \pm 2.3$ & $99.2 \pm 1.6$ \\
$\mathrm{ME}$ & $98.1 \pm 1.4^{*}$ & $100.1 \pm 1.0$ \\
\hline
\end{tabular}

${ }^{1}$ Mixed ration contained $70 \%$ concentrate and $30 \%$ chopped hay.

${ }^{2}$ Data are averaged over $4 \mathrm{~d}$ for each of 2 recording weeks for 10 calves on MIX treatment.

${ }^{3}$ Calculated as $100 \times$ (actual nutrient DMI/predicted nutrient DMI). Values equal to $100 \%$ indicate no sorting, $<100 \%$ indicate selective refusals of feed components high in that nutrient (sorting against), and $>100 \%$ indicate preferential consumption of feed components high in that nutrient (sorting for).

${ }^{* *} P \leq 0.01, * P \leq 0.05, \dagger P \leq 0.1$; difference in sorting values from $100 \%$.

fed MIX consumed, as a percentage of predicted intake, less NDF and more NFC and tended to consume less $\mathrm{ADF}$, as a percentage of predicted intake, than calves previously fed COM (Table 5). Thus, calves previously fed MIX were selecting against hay and for concentrate, whereas calves fed COM did not sort their diet after transition to the MIX diet in wk 9. Differences in feed sorting were consistent over time for the $3 \mathrm{wk}$ that calves were monitored while consuming the MIX ration. As a result of sorting to a greater extent than calves previously fed COM, calves previously fed MIX tended to consume, as a percentage of total DMI, less $\mathrm{NDF}$ and ADF and more NFC (Table 5). However, total nutrient intakes were not different between treatments (Table 5).

Feed sorting also differed between calves previously fed MIX and COM after transition to the novel TMR (Table 6), with calves maintaining their pattern of sorting. Calves previously fed MIX sorted the novel ration to a greater extent than calves previously fed COM, sorting against long particles and for short and fine particles. In contrast, calves fed COM performed little sorting of any particle size fraction after transition to the novel TMR.

\section{DISCUSSION}

The diet selected by calves exposed to different feed presentations evolved over time. In the week before weaning, both calves fed MIX and COM selected in favor of hay to a similar degree. Providing hay to calves before weaning is a subject of some controversy in the dairy industry (Coverdale et al., 2004; Castells et al., 2012), with reluctance to provide hay based on the possibility of reduced intake of concentrate (Hill et al., 2008), and impaired development of rumen papillae (Tamate et al., 1962). However, evidence also exists that a provision of high-fiber feedstuffs, such as hay, can increase concentrate intake and improve feed efficiency and rumen environment (Coverdale et al., 2004; Khan et al., 2011; Castells et al., 2012). Further, provision of hay has been found to reduce nonnutritive oral behavior in calves (Haley et al., 1998; Phillips, 2004; Castells et al., 2012), which may result from frustrated

Table 4. Effect of feed presentation treatments ${ }^{1}$ on intake of nutrients during the milk-feeding stage (measured during wk 6 ) and in the week following weaning (wk 8) ${ }^{2}$

\begin{tabular}{|c|c|c|c|c|c|c|c|c|}
\hline Item & \multicolumn{2}{|c|}{ Wk 6} & SE & $P$-value & \multicolumn{2}{|c|}{ Wk 8} & $\mathrm{SE}$ & $P$-value \\
\hline DMI, kg/d & 0.50 & 0.49 & 0.074 & 0.91 & 2.1 & 2.0 & 0.13 & 0.77 \\
\hline $\mathrm{ADF}, \% \mathrm{DMI}$ & 13.6 & 14.4 & 0.93 & 0.28 & 13.7 & 12.4 & 0.44 & 0.048 \\
\hline NFC, $\%$ DMI & 39.3 & 42.7 & 1.8 & 0.18 & 46.2 & 50.3 & 0.76 & 0.0013 \\
\hline CP, \% DMI & 21.1 & 19.6 & 1.8 & 0.21 & 18.3 & 18.5 & 0.19 & 0.41 \\
\hline $\mathrm{NFC}, \mathrm{kg} / \mathrm{d}$ & 0.20 & 0.22 & 0.032 & 0.70 & 0.95 & 1.0 & 0.032 & 0.040 \\
\hline $\mathrm{CP}, \mathrm{kg} / \mathrm{d}$ & 0.11 & 0.092 & 0.016 & 0.42 & 0.38 & 0.38 & 0.024 & 0.88 \\
\hline ME, Mcal & 1.4 & 1.3 & 0.19 & 0.88 & 5.6 & 5.6 & 0.37 & 0.97 \\
\hline
\end{tabular}

${ }^{1} \mathrm{MIX}=$ calves provided mixture of $70 \%$ concentrate and $30 \%$ chopped hay; $\mathrm{COM}=$ calves provided concentrate and chopped hay separately.

${ }^{2}$ Data are averaged by week for each calf per treatment $(\mathrm{n}=10$ for MIX, $\mathrm{n}=9$ for COM). 
Table 5. Effect of prior exposure to feed presentation treatments ${ }^{1}$ on dietary selection, assessed through nutrient intakes, whereas calves were all offered the MIX ration (measured during wk 9 and 11$)^{2}$

\begin{tabular}{|c|c|c|c|c|c|c|c|c|}
\hline \multirow[b]{2}{*}{ Nutrient } & \multicolumn{2}{|c|}{ Wk 9} & \multicolumn{2}{|c|}{ Wk 11} & \multirow[b]{2}{*}{ SE } & \multicolumn{3}{|c|}{$P$-value ${ }^{3}$} \\
\hline & MIX & $\mathrm{COM}$ & MIX & $\mathrm{COM}$ & & Wk & $\mathrm{T}$ & $\mathrm{Wk} \times \mathrm{T}$ \\
\hline \multicolumn{9}{|c|}{ Nutrient intake, $\%$ of predicted intake ${ }^{4}$} \\
\hline NDF & $97.5^{*}$ & 100.9 & $97.6^{*}$ & 100.1 & 0.98 & 0.12 & 0.043 & 0.63 \\
\hline $\mathrm{ADF}$ & $98.1 \dagger$ & 100.6 & $96.7^{* *}$ & 99.1 & 1.2 & 0.27 & 0.052 & 0.90 \\
\hline NFC & $102.2^{*}$ & 98.2 & $104.2^{* *}$ & 99.9 & 0.58 & 0.22 & 0.048 & 0.67 \\
\hline $\mathrm{CP}$ & 99.9 & $98.9^{*}$ & $101.5^{* *}$ & 100.1 & 0.41 & 0.12 & 0.096 & 0.79 \\
\hline \multicolumn{9}{|l|}{ Intake of nutrients } \\
\hline DMI, kg/d & 2.76 & 2.68 & 4.00 & 4.02 & 0.18 & $<0.001$ & 0.88 & 0.65 \\
\hline NDF, $\%$ of DMI & 25.4 & 26.3 & 26.9 & 27.5 & 0.68 & 0.0046 & 0.089 & 0.73 \\
\hline $\mathrm{ADF}, \%$ of $\mathrm{DMI}$ & 13.6 & 14.2 & 14.9 & 15.2 & 0.34 & 0.0056 & 0.087 & 0.76 \\
\hline NFC, $\%$ of DMI & 46.1 & 45.5 & 41.1 & 40.9 & 0.28 & $<0.001$ & 0.092 & 0.35 \\
\hline $\mathrm{CP}, \%$ of $\mathrm{DMI}$ & 17.4 & 17.2 & 20.0 & 20.0 & 0.29 & $<0.001$ & 0.50 & 0.95 \\
\hline $\mathrm{NDF}, \mathrm{kg} / \mathrm{d}$ & 0.69 & 0.70 & 1.08 & 1.10 & 0.05 & $<0.001$ & 0.88 & 0.80 \\
\hline $\mathrm{ADF}, \mathrm{kg} / \mathrm{d}$ & 0.38 & 0.38 & 0.60 & 0.61 & 0.029 & $<0.001$ & 0.85 & 0.92 \\
\hline
\end{tabular}

${ }^{1}$ MIX = calves provided mixture of $70 \%$ concentrate and $30 \%$ chopped hay; COM = calves provided concentrate and chopped hay separately. ${ }^{2}$ Data are averaged by week for each calf per treatment $(\mathrm{n}=10$ for MIX, $\mathrm{n}=9$ for COM).

${ }^{3} \mathrm{~T}=$ treatment; $\mathrm{Wk} \times \mathrm{T}=$ week by treatment interaction.

${ }^{4}$ Calculated as $100 \times$ (actual nutrient DMI/predicted nutrient DMI). Values equal to $100 \%$ indicate no sorting, $<100 \%$ indicate selective refusals of feed components high in that nutrient (sorting against), and $>100 \%$ indicate preferential consumption of feed components high in that nutrient (sorting for). Data are averaged over d 1 to 4 for each of 2 recording weeks postweaning for each calf per treatment (n $=10$ for MIX, $\mathrm{n}=9$ for $\mathrm{COM})$.

${ }^{* *} P \leq 0.01,{ }^{*} P \leq 0.05, \dagger P \leq 0.1$; difference in sorting values from $100 \%$.

feeding motivation (Redbo, 1990; Redbo and Nordblad, 1997), and are thus like other stereotypical behaviors (Mason and Latham, 2004), considered indicators of poor welfare. As all calves were provided hay in the present study, any benefits of hay are only speculative. It is worth noting, however, that the inclination for both treatment groups to selectively consume hay before weaning would suggest that calves are motivated to consume forage, either due to nutritional or behavioral needs, and that provision of forage may improve their welfare.
Calves on both feed presentation treatments increased selection in favor of concentrate in the week after weaning. Similarly, preferential consumption of the concentrate component compared with the hay component has been observed in growing heifers (DeVries and von Keyserlingk, 2009; Greter et al., 2010a) and adult cattle (Maekawa et al., 2002). Few studies have investigated diet selection of young calves. Montoro and Bach (2012) reported that calves offered 6 different individual ingredients, compared with a single mash starter ration, consumed an unbalanced CP to energy

Table 6. Effect of prior exposure to different feed presentation treatments ${ }^{1}$ on sorting (\%) of particle size fractions, whereas calves were fed the novel TMR (in wk 12 and 13$)^{2}$

\begin{tabular}{|c|c|c|c|c|c|c|c|c|}
\hline \multirow{2}{*}{$\begin{array}{l}\text { Sorting of particle } \\
\text { size fraction, } \%^{3}\end{array}$} & \multicolumn{2}{|c|}{ Wk 12} & \multicolumn{2}{|c|}{ Wk 13} & \multirow[b]{2}{*}{$\mathrm{SE}$} & \multicolumn{3}{|c|}{$P$-value ${ }^{4}$} \\
\hline & MIX & $\mathrm{COM}$ & MIX & COM & & $\mathrm{Wk}$ & $\mathrm{T}$ & $\mathrm{Wk} \times \mathrm{T}$ \\
\hline Long & $86.8^{* *}$ & 100.1 & $86.2^{* *}$ & $97.3 \dagger$ & 2.6 & 0.32 & 0.0044 & 0.45 \\
\hline Medium & 99.9 & 99.5 & 99.6 & 100.3 & 0.46 & 0.64 & 0.91 & 0.22 \\
\hline Short & $101.7^{*}$ & 100.4 & $101.8^{* *}$ & 100.2 & 0.74 & 0.19 & 0.015 & 0.18 \\
\hline Fine & $101.4^{*}$ & 99.3 & $101.0 \dagger$ & 98.1 & 1.0 & 0.31 & 0.048 & 0.59 \\
\hline
\end{tabular}

${ }^{1}$ MIX $=$ calves provided mixture of $70 \%$ concentrate and $30 \%$ chopped hay, COM = calves provided concentrate and chopped hay separately. ${ }^{2}$ Data are averaged by week for each calf per treatment ( $\mathrm{n}=10$ for MIX, $\mathrm{n}=9$ for COM).

${ }^{3}$ Sorting $\%=100 \times$ (actual particle size fraction DMI/predicted particle size fraction DMI). Values equal to $100 \%$ indicate no sorting, $<100 \%$ indicate selective refusals (sorting against), and $>100 \%$ indicate preferential consumption (sorting for). Data are averaged over $7 \mathrm{~d}$ for each of 2 recording weeks for 10 coarse calves and 9 fine calves. Particle size determined by Penn State Particle Separator, which separates the particles in 4 fractions: long $(>19 \mathrm{~mm})$, medium $(<19$ and $>8 \mathrm{~mm})$, short $(<8$ and $>1.18 \mathrm{~mm})$, and fine $(<1.18 \mathrm{~mm})$.

${ }^{4} \mathrm{~T}=$ treatment; $\mathrm{Wk} \times \mathrm{T}=$ week by treatment interaction.

${ }^{* *} P \leq 0.01, * P \leq 0.05, \dagger P \leq 0.1$; difference in sorting values from $100 \%$. 
ratio. These authors concluded that young calves were not capable of dietary selection based on nutrient requirements. The present study provided only 2 distinct feed types, which may have been more easily differentiated than the 6 provided by Montoro and Bach (2012). The increasing selection in favor of the higher energy concentrate over time suggests that calves in the present study may have been adjusting their diet to account for increased reliance on solid feed for energy that occurs after removal of milk (Drackley, 2008).

Feed presentation did not affect DMI or growth of the calves. Similarly, method of feed delivery of concentrate and forage does not appear to influence DMI or growth in weaned heifers (DeVries and von Keyserlingk, 2009; Greter et al., 2010a) or DMI in adult cattle (Maekawa et al., 2002). However, feed presentation affected the balance of nutrient intake. Although calves selected in favor of concentrate regardless of feed presentation, immediately after weaning, calves fed COM selected in favor of concentrate to a greater extent, consuming more concentrate as a percentage of DMI (indicated by greater NFC intake; Table 4). This result was reminiscent of similar selection differences between heifers provided concentrate and hay as a top-dressed ration or as a TMR (Greter et al., 2010a). Given that calves were exposed to different feed presentations for only a short period of time in the postweaning stage, it is unclear whether greater selection in favor of concentrate by calves fed COM compared with calves fed MIX may have been functional, supporting the high energy requirements at this stage of growth (Drackley, 2008), or detrimental, potentially reducing rumen $\mathrm{pH}$ and negatively effecting fermentation, as reported in older animals (Greter et al., 2010a). Further research is encouraged to investigate differences in the performance and rumen health of calves exposed to different feed presentations for a longer period of time.

Contrary to our hypothesis, early exposure to feed types provided as separate components decreased the extent of feed sorting as the calves aged. When provided the MIX ration in wk 9 to 11, calves previously exposed to MIX sorted in favor of concentrate, whereas calves previously fed COM did not sort in favor of either feed component after transition to the mixed ration. This was result was surprising. One possible explanation for this result is a difference between treatments in understanding of individual feed components. To select an appropriate diet, animals must be able to associate the sensory properties of each food type with the respective postingestive feedback (Forbes and Kyriazakis, 1995), a learning task made more difficult when feed types are offered as a mixture. Thus, it is possible that calves fed MIX sorted their ration to a greater extent than calves fed COM due to an impaired ability to balance an appropriate ration. Improved understanding of the function and consequences of dietary selection in young calves would shed light on this possible explanation. Differences in feed sorting in wk 9 and wk 11 resulted in a tendency for intake of NFC, NDF, and ADF as a percent of DMI to differ between treatments. Although this did not translate into significant differences in total nutrient intake or ADG, sorting may have had rumen health consequences that were not measured in the present study. For example, Greter et al. (2010a) reported that increased selection against forage did not affect ADG, but was associated with looser stools, which indicates reduced rumen $\mathrm{pH}$ (Krause and Oetzel, 2006). Thus, further research is encouraged to investigate the differences in performance and rumen health associated with dietary selection in young calves.

Alternatively, the effect of prior exposure to different feed presentations on sorting may be explained by differences in experience performing the motor skills required for feed sorting. Calves fed COM consumed a diet that contained more than $80 \%$ concentrate in wk 8 , yet these calves did not sort to maintain this level of concentrate intake after transition to the MIX diet, which contained only $70 \%$ concentrate. This abrupt change in the composition of the consumed diet suggests that dietary selection by calves previously fed COM was thwarted by provision of the feed types as a mixture. Given the greater feed sorting exhibited by calves previously familiarized with the MIX diet, it is possible that provision of the MIX diet early in life provided an opportunity for calves to develop the motor skills necessary for feed sorting. As discussed above, feed sorting of calves fed MIX mirrored dietary selection of calves fed $\mathrm{COM}$, with preference for concentrate, relative to hay, increasing over time. Thus, calves fed MIX may have been motivated to sort their ration early in life to accommodate changing preferences. Learning to sort may also have been facilitated by the dry nature of the MIX ration, as adult cattle exhibit increased feed sorting when provided a dry TMR (>80\% DM; Leonardi et al., 2005) and a TMR containing dry hay (Leonardi and Armentano, 2003). It is generally understood that motor skills develop as they are repeated (Bandura, 1977), and, thus, foraging motor skills develop in response to experience with particular feeds (Arnold and Maller, 1977; Provenza and Balph, 1987). Performance of feed sorting may then depend on prior opportunity to exercise the necessary motor skills. It is unclear, however, whether experience with different feed presentations at a critical timeframe around weaning has a long-term effect on performance of feeding sorting, or whether the effect observed in the present study is merely a delay in the development of the behavior due to lack of experience. Though the present results indicate that 
feed sorting develops quickly early in life after minimal experience with solid feed, the timeframe in which feed sorting develops in response to postweaning exposure to a mixed ration is unclear. It is interesting to note, however, that feed experiences around weaning have been found to have a greater influence on long-term feed preferences and feeding motor skills than similar experiences later in life (Arnold and Maller, 1977; Nolte et al., 1990).

In contrast to the present results, Greter et al., (2010b) exposed weaned heifers to different feed presentations for a period of $13 \mathrm{wk}$, but found no differences in feed sorting after all heifers were fed a TMR. Upon transition to the TMR, all heifers sorted against the long particles and for the short and fine particles. Those authors suggested that feed presentation has minimal effect on development of feed sorting in weaned heifers. Given the extent to which calves in the present trial were actively sorting a mixed ration at 6 wk of age, it seems likely that feed sorting develops rapidly early in life in response to feed management factors. In the study by Greter et al. (2010a), heifers were first exposed to the feed presentation treatments at approximately $21 \mathrm{wk}$ of age. It is possible that the development of feed sorting in these animals had already been facilitated by previous management factors.

Interestingly, differences in feed sorting patterns between calves previously exposed to different feed presentations persisted after transition to the novel TMR. Sorting of the novel TMR immediately upon transition was surprising, given that the feed components were novel and the calves had no previous opportunity to learn about the individual feed components. The persistence of sorting by calves previously fed MIX after transition to the novel TMR suggests that sorting patterns and abilities, once learned, may persist despite ration changes. Calves previously fed MIX sorted the novel TMR against the long particle fraction, which contained solely forage (mostly long haylage and some long corn silage particles; Table 2). That long particle fraction resembled hay most closely in the MIX ration, both in terms of particle size and nutrient composition. This consistency of sorting patterns immediately after transition to the novel ration suggests that sorting may either depend on perception of palatability of different components, which is subject to previous feed experiences (Provenza et al., 1992), or on previously established sorting motor patterns, with sorting driven by selection of certain particle sizes.

It should be noted that differences in feed sorting between treatments were maintained for the 2 wk that calves were followed on the novel TMR; thus, differences between treatments persisted for the full $5 \mathrm{wk}$ during which both groups were given mixed rations.
Further research is encouraged to assess the duration as well as the longer-term consequences of the differences in feed sorting that result from early exposure to different feed presentations. A longer-term study would also provide insight into whether exposure to different feed presentations early in life only delays development of feed sorting or whether it may result in persistent differences in the performance of feed sorting.

\section{CONCLUSIONS}

Providing dairy calves with hay and concentrate either as a mixed ration or as separate components did not affect feed intake or growth. Regardless of feed presentation, calves selected in favor of hay in the week before weaning and increased selection in favor of concentrate after weaning. Provision of feed types as separate components resulted in greater intake of concentrate than provision of the mixed ration. After all calves were provided the mixed ration, calves previously exposed to the mixed ration sorted in favor of concentrate, whereas calves previously provided separate components did not sort. Upon transition to a novel TMR, differences in feed sorting persisted, with calves previously fed a mixed ration maintaining greater feed sorting. These results show that early exposure to different feed presentations affected feed sorting for at least 5 wk after the differential feeding treatments. Thus, these results suggest that methods of feeding preweaning calves could have the potential to reduce, or at least delay, the emergence of feed sorting.

\section{ACKNOWLEDGMENTS}

We thank the staff and students at the University of Guelph, Kemptville Campus Dairy Education and Research Centre. In particular, we thank Megan Bruce, Alexa Mains, and Nancy Stonos of the University of Guelph, Kemptville Campus for their technical assistance. This project was funded through a Natural Sciences and Engineering Research Council of Canada (Ottawa, Ontario, Canada) Discovery Grant (awarded to T. J. DeVries), an Ontario Ministry of Agriculture, Food and Rural Affairs (Guelph, Ontario, Canada)/ University of Guelph Production Systems research grant, and support from Nutreco Canada Inc. (Guelph, Ontario, Canada). This project was also supported through contributions from the Canadian Foundation for Innovation (Ottawa, ON, Canada) and the Ontario Research Fund (Ministry of Research and Innovation, Toronto, Ontario, Canada).

\section{REFERENCES}

AOAC International. 2000. Official Methods of Analysis. Vol. I. 17th ed. AOAC International, Arlington, VA. 
Appleby, M. 2001. Performance and feeding behaviour of calves on ad libitum milk from artificial teats. Appl. Anim. Behav. Sci. 74:191-201.

Arnold, G. W., and R. A. Maller. 1977. Effects of nutritional experience in early and adult life on the performance and dietary habits of sheep. Appl. Anim. Ethol. 3:5-26.

Bandura, A. 1977. Social Learning Theory. Prentice Hall, Englewood Cliffs, NJ.

Borland, K., and E. M. Kesler. 1979. Complete rations for Holstein calves 8 to 18 weeks of age. J. Dairy Sci. 62:304-309.

Castells, L., A. Bach, G. Araujo, C. Montoro, and M. Terré. 2012. Effect of different forage sources on performance and feeding behavior of Holstein calves. J. Dairy Sci. 95:286-293.

CCAC (Canadian Council on Animal Care). 2009. CCAC Guidelines on the Care and Use of Farm Animals in Research, Teaching and Testing. Canadian Council on Animal Care, Ottawa, Canada.

Coppock, C. E., D. L. Bath, and B. Harris Jr. 1981. From feeding to feeding systems. J. Dairy Sci. 64:1230-1249.

Coverdale, J. A., H. D. Tyler, J. D. Quigley, and J. A. Brumm. 2004. Effect of various levels of forage and form of diet on rumen development and growth in calves. J. Dairy Sci. 87:2554-2562.

De Paula Vieira, A., V. Guesdon, A. M. de Passillé, M. Vonkeyserlingk, and D. Weary. 2008. Behavioural indicators of hunger in dairy calves. Appl. Anim. Behav. Sci. 109:180-189.

DeVries, T. J., and M. A. G. von Keyserlingk. 2009. Short communication: Feeding method affects the feeding behavior of growing dairy heifers. J. Dairy Sci. 92:1161-1168.

DeVries, T. J., M. A. G. von Keyserlingk, and K. A. Beauchemin. 2005. Frequency of feed delivery affects the behavior of lactating dairy cows. J. Dairy Sci. 88:3553-3562.

Drackley, J. K. 2008. Calf nutrition from birth to breeding. Vet. Clin. North Am. Food Anim. Pract. 24:55-86.

Flores, E. R., F. D. Provenza, and D. F. Balph. 1989. The effect of experience on the foraging skill of lambs: Importance of plant form. Appl. Anim. Behav. Sci. 23:285-291.

Forbes, J. M., and I. Kyriazakis. 1995. Food preferences in farm animals: Why don't they always choose wisely? Proc. Nutr. Soc. 54:429-440.

Greter, A. M., K. E. Leslie, G. J. Mason, B. W. McBride, and T. J. Devries. 2010a. Effect of feed delivery method on the behavior and growth of dairy heifers. J. Dairy Sci. 93:1668-1676.

Greter, A. M., K. E. Leslie, G. J. Mason, B. W. McBride, and T. J. DeVries. 2010b. Feed delivery method affects the learning of feeding and competitive behavior in dairy heifers. J. Dairy Sci. 93:3730-3737.

Haley, D. B., J. Rushen, I. J. Duncan, T. M. Widowski, and A. M. De Passillé. 1998. Effects of resistance to milk flow and the provision of hay on nonnutritive sucking by dairy calves. J. Dairy Sci. 81:2165-2172.

Hill, T. M., H. G. Bateman, J. M. Aldrich, and R. L. Schlotterbeck. 2008. Effects of the amount of chopped hay or cottonseed hulls in a textured calf starter on young calf performance. J. Dairy Sci. 91:2684-2693.

Jasper, J., and D. M. Weary. 2002. Effects of ad libitum milk intake on dairy calves. J. Dairy Sci. 85:3054-3058.

Khan, M. A., D. M. Weary, and M. A. G. von Keyserlingk. 2011. Hay intake improves performance and rumen development of calves fed higher quantities of milk. J. Dairy Sci. 94:3547-3553.

Kononoff, P. J., A. J. Heinrichs, and D. R. Buckmaster. 2003. Modification of Penn State forage and total mixed ration particle separator and the effects of moisture content on its measurements. J. Dairy Sci. 86:1858-1863.

Krause, K., and G. Oetzel. 2006. Understanding and preventing subacute ruminal acidosis in dairy herds: A review. Anim. Feed Sci. Technol. 126:215-236.

Leonardi, C., and L. E. Armentano. 2003. Effect of quantity, quality, and length of alfalfa hay on selective consumption by dairy cows. J. Dairy Sci. 86:557-564.
Leonardi, C., and L. E. Armentano. 2007. Feed selection by dairy cows fed individually in a tie-stall or as a group in a free-stall barn. J. Dairy Sci. 90:2386-2389.

Leonardi, C., K. J. Shinners, and L. E. Armentano. 2005. Effect of different dietary geometric mean particle length and particle size distribution of oat silage on feeding behavior and productive performance of dairy cattle. J. Dairy Sci. 88:698-710.

Maekawa, M., K. A. Beauchemin, and D. A. Christensen. 2002. Effect of concentrate level and feeding management on chewing activities, saliva production, and ruminal $\mathrm{pH}$ of lactating dairy cows. J. Dairy Sci. 85:1165-1175.

Mason, G. J., and N. R. Latham. 2004. Can't stop, won't stop: Is stereotypy a reliable animal welfare indicator? Anim. Welf. 13:S57S69.

Miller-Cushon, E. K., and T. J. DeVries. 2009. Effect of dietary dry matter concentration on the sorting behavior of lactating dairy cows fed a total mixed ration. J. Dairy Sci. 92:3292-3298.

Miller-Cushon, E. K., and T. J. DeVries. 2010. Feeding amount affects the sorting behavior of lactating dairy cows. Can. J. Anim. Sci. $90: 1-7$.

Montoro, C., and A. Bach. 2012. Voluntary selection of starter feed ingredients offered separately to nursing calves. Livest. Sci. 149:6269 .

Montoro, C., E. K. Miller-Cushon, T. J. DeVries, and A. Bach. 2013. Effect of physical form of forage on performance, feeding behavior, and digestibility of Holstein calves. J. Dairy Sci. 96:1117-1124.

Nolte, D. L., F. D. Provenza, and D. F. Balph. 1990. The establishment and persistence of food preferences in lambs exposed to selected foods. J. Anim. Sci. 68:998-1002.

NRC. 2001. Nutrient Requirements of Dairy Cattle. 7th rev. ed. Natl. Acad. Sci., Washington, DC.

Phillips, C. J. C. 2004. The effects of forage provision and group size on the behavior of calves. J. Dairy Sci. 87:1380-1388.

Provenza, F. D., and D. F. Balph. 1987. Diet learning by domestic ruminants: Theory, evidence and practical implications. Appl. Anim. Behav. Sci. 18:211-232.

Provenza, F. D., and D. F. Balph. 1988. Development of dietary choice in livestock on rangelands and its implications for management. J. Anim. Sci. 66:2356-2368.

Provenza, F. D., J. A. Pfister, and C. D. Cheney. 1992. Mechanisms of learning in diet selection with reference to phytotoxicosis in herbivores. J. Range Manage. 45:36-45.

Redbo, I. 1990. Changes in duration and frequency of stereotypies and their adjoining behaviours in heifers, before, during and after the grazing period. Appl. Anim. Behav. Sci. 26:57-67.

Redbo, I., and A. Nordblad. 1997. Stereotypies in heifers are affected by feeding regime. Appl. Anim. Behav. Sci. 53:193-202.

SAS Institute. 2008. SAS User's Guide. SAS Institute Inc., Cary, NC.

Simitzis, P. E., J. A. Bizelis, S. G. Deligeorgis, and K. Feggeros. 2008 Effect of early dietary experiences on the development of feeding preferences in semi-intensive sheep farming systems-A brief note. Appl. Anim. Behav. Sci. 111:391-395.

Squibb, R. C., F. D. Provenza, and D. F. Balph. 1990. Effect of age of exposure on consumption of a shrub by sheep. J. Anim. Sci. 68:987-997.

Stanton, A. L., D. F. Kelton, S. J. LeBlanc, J. Vormuth, L. K. Fox, and K. E. Leslie. 2013. The effect of treatment with the longacting antibiotic tulathromycin upon arrival at a heifer raising facility on disease and growth in commercial dairy heifers. Am. Vet. Med. Assoc. In press.

Tamate, H., A. D. McGilliard, N. L. Jacobson, and R. Getty. 1962 Effect of various dietaries on the anatomical development of the stomach in the calf. J. Dairy Sci. 45:408-420.

Van Soest, P. J., J. B. Robertson, and B. A. Lewis. 1991. Methods for dietary fiber, neutral detergent fiber, and nonstarch polysaccharide in relation to animal nutrition. J. Dairy Sci. 74:3583-3597. 